\title{
Inovações, Pequenas Empresas e Interações com Instituições de Ensino/Pesquisa em Arranjos Produtivos Locais de Setores de Tecnologia Avançada*
}

\author{
Marisa dos Reis Azevedo Botelho \\ Professora Adjunto IV do Instituto de Economia da Universidade Federal de Uberlândia (UFU) \\ Michelle de Castro Carrijo \\ Doutoranda no Instituto de Economia da Universidade Federal de Uberlândia (UFU) \\ Gilsa Yumi Kamasaki \\ Mestre em Economia, Técnica no Ministério da Ciência e Tecnologia/SEPIN
}

\section{RESUMO}

O trabalho analisa as especificidades da geração de inovações por empresas de pequeno porte, destacando-se, em especial, as possibilidades advindas das interações de pequenas empresas com instituições de ensino/pesquisa em arranjos produtivos locais. Apresenta-se, inicialmente, uma discussão teórico/conceitual fundamentada em desenvolvimentos recentes do enfoque neo-schumpeteriano. $\mathrm{Na}$ seqüência, são apresentados alguns dados de duas aglomerações presentes no estado de Minas Gerais, a saber, a aglomeração de empresas de eletrônica/telecomunicaçôes de Santa Rita do Sapucaí e a de biotecnologia de Belo Horizonte. A pesquisa de campo obteve dados, nos quais as conclusōes deste trabalho se baseiam, sobre a geração de inovaçōes bem como sobre as fontes de informação utilizadas pelas empresas neste processo.

\footnotetext{
* Agradecemos aos pareceristas anônimos as valiosas críticas e sugestões, cuja incorporação permitiu aprimorar o trabalho.
} 
PalaVras-Chave | Instituições de Ensino/Pesquisa; Pequenas Empresas; Inovação; Desenvolvimento Regional

Códigos JEL | I23; L25; O31; R58

\section{ABSTRACT}

In this paper the particularities of the generation of innovations by small enterprises are discussed. Of special interest are the possibilities coming from the interactions between small enterprises and education/research institutions in local clusters. The discussion begins with a theoretical/conceptual approach based on some recent neoschumpeterian developments. Next some data are presented, especially from two clusters in the state of Minas Gerais, namely, the Santa Rita do Sapucaí electronics/ telecommunications cluster and the Belo Horizonte biotechnology cluster. The empirical research provided data, on which our conclusions are based, concerning the generation of innovation as well as the sources of information the enterprises used in this process.

KEYWORDS I Education/Research Institutions; Small Enterprises; Innovation; Regional Development

JEL-CODES I I23; L25; O31; R58 


\section{Introdução}

O tema da inovação tecnológica por parte de pequenas empresas ${ }^{1}$ (PEs) ganhou relevância nas últimas décadas, motivado por recentes desenvolvimentos teóricos, em especial, no enfoque neo-schumpeteriano, bem como pela divulgação de resultados de pesquisas empíricas que constataram uma participação significativa de inovações empreendidas em empresas de menor porte em alguns setores produtivos. Pode-se afirmar que a verificada participação de PEs nas inovações industriais não era esperada, dada à relação que se estabelecia, sobretudo em trabalhos acadêmicos, entre atividades de pesquisa e desenvolvimento (restrita a grandes empresas em função do seu alto custo) e inovações, considerando-se tais atividades como o principal determinante das inovações.

As pesquisas que se seguiram, em especial as desenvolvidas no âmbito do enfoque neo-schumpeteriano, mostraram a impossibilidade de tratar a atividade de inovação somente a partir de gastos formais de P\&D. Verificou-se, a partir de pesquisas empíricas, uma teia de relaçōes estabelecidas pelas empresas que influenciam significativamente as atividades produtivas em geral, e as inovativas em particular. Relações com clientes e fornecedores, com empresas concorrentes (especialmente em fases pré-competitivas) e com institutos de pesquisa e/ou universidades, figuraram nas pesquisas como as mais importantes. A proximidade geográfica entre empresas e instituições de apoio também aparece como elemento importante para a atividade de inovação, dada a característica parcialmente tácita do conhecimento que origina as inovações. Dessa constatação decorreu uma série de estudos sobre as especificidades da presença das empresas em aglomerações setoriais, com especial destaque para as possibilidades de superação das debilidades das empresas de pequeno porte quando presentes em aglomerações.

1 Quanto à definição de PEs, o conceito fundamental é o de pequeno capital, ou seja, empresas com menor poder financeiro, tecnológico e de mercado, nos termos desenvolvidos por Steindl (1990). Ao longo deste trabalho, para o tratamento empírico diversas definições serão utilizadas, em função da não uniformidade verificada na literatura analisada. Parte dos trabalhos internacionais considera as pequenas e médias empresas em conjunto, normalmente definidas para até 500 empregados. No Brasil são utilizados diferentes critérios para a classificação das empresas por porte, de acordo com os objetivos da classificação. No âmbito do SEBRAE (Serviço Brasileiro de Apoio a Micro e Pequena Empresa) e da pesquisa de campo aqui apresentada, são consideradas PEs industriais aquelas com até 99 empregados. As diversas definições e as devidas qualificações serão apresentadas à medida que se fizerem necessárias para o desenvolvimento do trabalho. Utiliza-se ao longo do trabalho o termo PE ou empresas de pequeno porte indistintamente, a fim de referir-se às empresas consideradas no âmbito deste trabalho. 
Por outro lado, verificou-se também a impropriedade de medir as atividades de inovação somente a partir de patentes registradas em órgãos competentes. Diversos tipos de inovação, sobretudo as classificadas como incrementais na literatura neo-schumpeteriana, não são, em geral, patenteáveis, mas apresentam-se de suma importância para o desenvolvimento tecnológico em geral e, principalmente, para a competitividade das empresas.

Construiu-se, assim, um arcabouço teórico que permite entender como as PEs superam as debilidades intrínsecas ao porte e participam ativa e positivamente das atividades de inovação, o que significou também tornar mais complexas as análises clássicas sobre a contribuição das empresas de pequeno porte ao desenvolvimento econômico, quase sempre restritas ao emprego.

À luz dessas referências, o presente trabalho discute a participação das PEs em atividades de inovação, com destaque para as interações das empresas com universidades e/ou centros de pesquisa. O objetivo principal é o de colocar em relevo o papel que podem assumir instituições de ensino/pesquisa como principal fonte de informações para a atividade de inovações por PEs. Após esta introdução, a segunda seção apresenta um resumo das contribuições conceituais sobre esse tema, com foco na experiência internacional. As seções 3 e 4 apresentam informações de recente pesquisa de campo ${ }^{2}$ realizada em duas aglomerações de empresas presentes no estado de Minas Gerais, respectivamente a de empresas de eletrônica e telecomunicações de Santa Rita do Sapucaí e a de empresas de biotecnologia de Belo Horizonte. As informações referem-se às atividades de inovação e às respectivas fontes de obtenção de informações indicadas pelas empresas, onde se destacam as relações com instituições de ensino e pesquisa presentes no local. Por fim, apresentam-se as considerações finais.

2 Pesquisas de campo realizadas no âmbito do projeto "Micro e Pequenas Empresas em Arranjos Produtivos Locais no Brasil", financiado pelo SEBRAE Nacional e coordenado pelo Prof. Renato Campos, do Centro de Pesquisas Socioeconômicas da Universidade Federal de Santa Catarina. Nas duas aglomerações foram entrevistadas empresas por meio da aplicação de questionários padrão, bem como instituições de apoio presentes nas localidades, a fim de complementar as informações obtidas das empresas. O que se apresenta aqui, nos dois casos analisados, é uma parte da pesquisa, a que se refere às atividades de inovação das empresas. 


\section{Pequenas empresas e inovação tecnológica}

A relação entre PEs e inovação tecnológica tem sido bastante discutida nos últimos anos. Grande parte dos trabalhos que tratam desse tema tem como ponto de partida da análise o aparente paradoxo - a esperada "esmagadora" participação das grandes empresas (GEs) na atividade de inovação oriunda de seus laboratórios de $\mathrm{P} \& \mathrm{D}$ e a verificada (empiricamente) significativa participação de PEs em alguns setores produtivos. ${ }^{3}$ A tese segundo a qual as GEs seriam o veículo principal da atividade de inovação encontra-se, principalmente, no rol das contribuições de Schumpeter e foi, posteriormente, difundida por Galbraith. De acordo com esse último autor, “... não há ficção mais agradável do que a de que a mudança tecnológica é produto do talento inigualável do pequeno homem forçado pela competição a empregar sua esperteza para se sair melhor que seu vizinho. Infelizmente, é uma ficção" (Galbraith, 1956 apud Audretsch, 1994:23).

A primazia das GEs na inovação seria função direta do novo conhecimento gerado por suas atividades de pesquisa, atividades essas restritas às empresas de grande porte em função do montante de recursos requeridos. Essa proposição é a base da "knowledge production function", derivada das contribuições de Schumpeter (Griliches, 1979 apud Audretsch \& Vivarelli, 1994). Os gastos na manutenção das atividades de $\mathrm{P} \& \mathrm{D}$ das empresas são então considerados o principal insumo e a principal medida da inovação.

A partir dessa proposição, a geração de novo conhecimento (materializada em novos produtos e/ou processos) por meio da manutenção de atividades de P\&D de forma sistemática só é acessível a empresas maiores, em função dos altos custos e riscos característicos desse tipo de atividade. Ademais, o novo conhecimento originado nos laboratórios de P\&D das GEs apresenta altos graus de apropriabilidade e cumulatividade, distanciando-se das características de public good.

\footnotetext{
3 "... um paradoxo, porque é uma observação bem conhecida que o volume maior de P\&D é concentrado nas maiores corporações industriais (Scherer, 1991). E, de acordo com um dos mais predominantes modelos de mudança tecnológica (Griliches, 1979), a produção de inovações é produto do conhecimento que gera insumos, mais notavelmente P\&D. [Sabe-se] que pequenas empresas são a máquina da atividade de inovação em certas indústrias apesar da falta óbvia de atividades formais de P\&D..." (Audretsch \& Vivarelli, 1994:225-6). A esse respeito ver também Audretsch (1994) e Acs \& Audretsch (1990).
} 
No entanto, nas décadas de 1970 e 1980 verificou-se que uma parcela significativa das inovações industriais originou-se em pequenas e médias empresas (PMEs). Essa constatação foi possibilitada primeiramente pelos dados compilados pelo SPRU (Science Policy Research Unit), da Universidade de Sussex na Inglaterra.

Os trabalhos que divulgaram inicialmente as informações desse banco de dados mostraram uma participação significativa das PMEs inglesas na inovação. Entre os anos 1975-83, as empresas com menos de 500 empregados foram responsáveis por aproximadamente $25 \%$ do total das inovações introduzidas no setor manufatureiro. Nos últimos anos da coleta de dados (1981-83), aproximadamente um terço das inovações ocorreram em PMEs (Tether et al., 1997). ${ }^{4}$

Os setores que apresentaram participação maior na geração de inovações foram: instrumentos mecânicos e de engenharia, maquinaria não-elétrica, equipamentos elétricos, química e instrumentos (Acs \& Audretsch, 1990).

Os dados oriundos da Small Business Administration Innovation Data Base (EUA), divulgados por Acs e Audretsch (1990) mostraram resultados semelhantes aos do SPRU, principalmente em termos dos setores nos quais as PMEs têm participação elevada. Esses dados referem-se às inovações introduzidas no mercado norte-americano em 1982, considerando-se como inovaçôes os novos produtos, processos ou serviços que resultaram do desenvolvimento de uma invenção. ${ }^{5}$

A Tabela 1 apresenta os principais dados analisados por Acs e Audretsch.

4 O trabalho de Tether et al. (1997) mostra que os dados do SPRU foram superestimados nos primeiros trabalhos que os divulgaram. Uma avaliação mais cuidadosa desses dados mostrou que no período considerado (197583), as PMEs foram responsáveis por cerca de $20 \%$ do total das inovações na indústria inglesa. No período 1981-82 há um aumento na participação das empresas com menos de 500 empregados para 28,5\% aproximadamente. Os autores avaliam que essa revisão muda a conclusão anterior que assinalava uma participação das PMEs na inovação maior que a sua contribuição para o emprego. Com a revisão, as PMEs passam a contribuir para o emprego e a inovação em proporções semelhantes.

5 A pesquisa que originou os dados apresentados por Acs \& Audretsch (1990) foi efetuada por uma empresa privada (The Futures Group), contratada pelo Small Business Administration. A pesquisa foi elaborada mediante o acompanhamento de informações coletadas em aproximadamente 100 revistas especializadas nos diversos ramos industriais. 
Inovações, Pequenas Empresas e Interações com Instituições de

Ensino/Pesquisa em APLs de Setores de Tecnologia Avançada

TABELA 1

Número de inovações de grandes e pequenas empresas nas indústrias mais inovadoras (1982)

\begin{tabular}{|c|c|c|c|}
\hline Indústria & $\begin{array}{l}\text { Inovações } \\
\text { totais }\end{array}$ & $\begin{array}{l}\text { Inovações de } \\
\text { grandes firmas }\end{array}$ & $\begin{array}{c}\text { Inovações de } \\
\text { pequenas firmas }\end{array}$ \\
\hline Equipamento de computação eletrônica & 395 & 158 & 227 \\
\hline Instrumentos de controle de processo & 165 & 68 & 93 \\
\hline Equipamento de comunicação (rádio e TV) & 157 & 83 & 72 \\
\hline Produtos farmacêuticos & 133 & 120 & 13 \\
\hline Componentes eletrônicos & 128 & 54 & 73 \\
\hline Instrumentos científicos e de engenharia & 126 & 43 & 83 \\
\hline Semicondutores & 122 & 91 & 29 \\
\hline Produtos plásticos & 107 & 22 & 82 \\
\hline Equipamento fotográfico & 88 & 79 & 9 \\
\hline Máquinas de escritório & 77 & 67 & 10 \\
\hline Medidores de eletricidade & 77 & 28 & 47 \\
\hline Instrumentos e materiais cirúrgicos & 67 & 54 & 13 \\
\hline Equipamentos médicos e cirúrgicos & 66 & 30 & 36 \\
\hline Maquinário industrial especial & 64 & 43 & 21 \\
\hline Controles industriais & 61 & 15 & 46 \\
\hline Cosméticos & 59 & 41 & 18 \\
\hline Válvulas e conexões & 54 & 20 & 33 \\
\hline Eletrodomésticos e ventiladores & 53 & 47 & 6 \\
\hline Equipamentos de medida e controle & 52 & 3 & 45 \\
\hline Maquinaria para produtos alimentares & 50 & 37 & 12 \\
\hline Motores e geradores & 49 & 39 & 10 \\
\hline Resinas e materiais plásticos & 45 & 30 & 15 \\
\hline Produtos químicos inorgânicos industriais & 40 & 32 & 8 \\
\hline Aparelhos receptores de rádio e TV & 40 & 35 & 4 \\
\hline Ferramentas manuais & 39 & 27 & 11 \\
\hline Placas manufaturadas & 38 & 29 & 9 \\
\hline Estruturas metálicas & 35 & 12 & 17 \\
\hline Bombas e equipamentos para bombear & 34 & 18 & 16 \\
\hline Lentes e instrumentos óticos & 34 & 12 & 21 \\
\hline Materiais sanitários e para polir & 33 & 13 & 19 \\
\hline Caminhões e tratores & 33 & 13 & 20 \\
\hline Produtos medicinais e botânicos & 32 & 27 & 5 \\
\hline Aeronaves & 32 & 31 & 1 \\
\hline Controles ambientais & 32 & 22 & 10 \\
\hline
\end{tabular}

Fonte: U.S. Small Business Administration Innovation Data Base, in Acs \& Audretsch, 1990, p. 13-4.

Obs.: 1) os dados referem-se a inovações introduzidas na indústria dos Estados Unidos em 1982 e resultam de invenções realizadas, em média, 4,3 anos antes;

2) são consideradas grandes empresas aquelas que possuem mais de 500 empregados e pequenas empresas as que possuem até 500 empregados;

3) as inovações de grandes e pequenas empresas nem sempre coincidem com a soma total das inovações porque várias delas não podem ser classificadas de acordo com o tamanho da empresa. 
Dentre os 34 setores $^{6}$ considerados como os mais inovadores da indústria norte-americana, 14 apresentam participação de PMEs no total de inovações de aproximadamente $50 \%$ ou mais. Setores como instrumentos científicos e de engenharia, produtos plásticos, controles industriais e dispositivos de medição e controle destacam-se com mais de dois terços do total de inovações realizadas por PMEs. Outros setores nos quais as PMEs apresentam participação importante na inovação são os de equipamentos eletrônicos de computação, instrumentos de controle de processos, componentes eletrônicos e instrumentos para medir eletricidade. Como características comuns, estes setores apresentam inúmeras oportunidades tecnológicas e estruturas de demanda diferenciadas, cujos requerimentos tecnológicos específicos dificultam a produção em série e favorecem a existência de nichos. Em alguns desses setores, as inovações podem ser atribuídas à fase do ciclo do produto, especialmente os setores da fronteira tecnológica.

Algumas observações devem ser feitas quanto aos dados da Tabela 1. Em primeiro lugar, em alguns setores o número de empregados não é um bom indicador de tamanho da empresa (por exemplo, setores que operam na fronteira tecnológica e que produzem bens altamente sofisticados como os de equipamentos eletrônicos de computação e os de instrumentos de controle de processos). Ademais, o recente processo de reestruturação das GEs foi acompanhado, em grande medida, de diminuição no número de empregados, o que determina a necessidade de se reavaliar a tradicional classificação de porte das empresas. Em segundo, os dados não distinguem quais inovações são realizadas em empresas pequenas daquelas provenientes de empresas de tamanho médio. Dessa forma, as informações contidas na Tabela 1 permitem algumas inferências, mas não uma análise mais aprofundada.

Igualmente se apresentam informações mais recentes contidas na CIS3 (Third Community Innovation Survey), para o período 1998-2000. A despeito de apresentar um amplo painel de informações sobre as atividades de inovação no âmbito da União Européia, dificuldades de análise decorrem da ausência de dados mais desagregados que permitam verificar as especificidades setoriais da participação de PEs em inovações. Dentre as informações apresentadas neste estudo, destaque-se que dentre as PEs industriais, $40 \%$ relataram

6 Classificação dos setores segundo o SIC (Standard Industrial Classification), em termos de quatro dígitos. 
atividades de inovação no período considerado, enquanto o percentual encontrado para as grandes empresas foi de $80 \%$ e para as médias de $63 \%{ }^{7}$ Apesar das diferenças, pode-se considerar bastante expressiva a participação das PEs européias na inovação.

Em suma, o que as pesquisas têm mostrado é que, apesar de normalmente se verificar uma relação direta entre inovações e tamanho de empresas, tal relação não é linear em todos os setores. ${ }^{8}$ A pesquisa de Acs e Audretsch (1990:57) conclui que

“... a vantagem relativa de grandes firmas tende a ser promovida em indústrias que são capital-intensivas, concentradas e altamente sindicalizadas. Em contraste, nas induistrias que são altamente inovadoras e compostas predominantemente por firmas grandes, a vantagem relativa na inovação é sustentada pelas firmas pequenas. "[como única alternativa para se manterem no mercado]. ${ }^{9}$

Documento da OECD (1993) sobre a relação entre tecnologia e competitividade em PEs ressalta que, em geral, as PEs inovadoras apresentam: i) um gerente/proprietário qualificado em assuntos técnicos relacionados à especialização da empresa ou, ii) pessoal empregado com altos níveis de qualificação formal. A utilização desse skilled labour torna-se a "ponte" com fontes externas de tecnologia.

Esses resultados são compatíveis com a hipótese de S. Winter, analisada por Acs e Audretsch (1990), de que a inovação nas PEs emana de um regime tecnológico diferente do das GEs (o entrepreneurial regime em oposição ao

7 Esta pesquisa considerou como pequenas empresas aquelas com dez a 49 empregados, médias empresas as que possuíam de 50 a 249 empregados e grandes aquelas com mais de 250 empregados. Esta classificação tem a vantagem de permitir diferenciar o segmento das pequenas e médias empresas e, ademais, a de adotar uma classificação mais condizente com a dinâmica recente de desverticalização de atividades e diminuição dos quadros de pessoal adotados pelas empresas.

8 O trabalho de Symeonidis (1996) apresenta uma resenha da literatura recente sobre esse tema. Também conclui que não existem evidências empíricas que sustentem a hipótese de uma relação linear entre inovação e tamanho da empresa.

9 A utilização das informações provenientes do SPRU permite a Dosi (1988:1151-2) conclusão semelhante - "... em setores com altas oportunidades tecnológicas (química, elétrica/eletrônica) as firmas inovadoras podem ser encontradas e altamente representadas por aquelas que são muito grandes e aquelas que são muito pequenas (...) Inversamente, na maquinaria e engenharia mecânica (...) uma proporção relativamente maior de inovações é empreendida por firmas pequenas...". 
routinized regime). Em indústrias fortemente inovadoras e nas quais o skilled labour tem papel importante, as PEs apresentam vantagem na inovação. ${ }^{10}$

Nos termos da classificação de Pavitt (1992:215) quanto às diferenças setoriais da inovação,

"pequenas firmas inovadoras são tipicamente especializadas nas suas estratégias tecnológicas, concentram-se em inovaçōes de produto para produtores específicos, como máquinas-ferramenta, instrumentos científicos, químicos especializados ou software. Sua força estratégica está na habilidade de combinar tecnologia com necessidades específicas do cliente. As tarefas estratégicas-chave estão em achar e manter um nicho estável de produto e tirar benefícios sistematicamente da experiência do usuário."

A literatura que trata desse tema destaca algumas hipóteses (não excludentes) para a explicação da vantagem competitiva das PMEs na inovação em alguns setores industriais. Uma primeira hipótese diz respeito às fontes de geração de conhecimento. Tomando como verdadeira a relação direta entre conhecimento e inovação, tem-se investigado a importância de outras fontes de geração de conhecimento, em especial as universidades e os centros de pesquisa públicos. Como o conhecimento gerado nessas instituições é, em grande medida, de caráter público (public good), torna-se importante apreender a forma de difusão desse conhecimento. Pois bem, pesquisas mostraram que as PEs exploram de maneira mais eficiente os spillovers dos laboratórios universitários, enquanto as GEs exploram melhor o conhecimento gerado em seus próprios laboratórios (Audretsch \& Vivarelli, 1994). Vale dizer, quando o conhecimento necessário à geração de inovações é produzido externamente à indústria, as possibilidades para as novas e PEs são maiores (Acs \& Audretsch, 1990).

A análise de Rothwell e Beesley (1989) sobre as PEs inglesas chegou a conclusões idênticas. Utilizando a banco de dados do SPRU, estes autores

\footnotetext{
10 Essas observações determinam, logicamente, o questionamento do montante gasto em P\&D pelas empresas como variável proxy da atividade de inovação - "... P\&D é um insumo e não um produto do processo de inovação." (Audretsch \& Vivarelli, 1994:227). Diversos autores argumentam que os gastos em P\&D não captam, por exemplo, as atividades informais de pesquisa (Dosi, 1988); de outro lado, também as inovações não patenteadas (especialmente as incrementais) não são captadas por indicadores tradicionais.
} 
mostram que as PMEs inovativas inglesas apresentaram altos níveis de vínculos em P\&D com outras empresas, com instituições de infra-estrutura e de $\mathrm{C} \& \mathrm{~T}$ governamentais. Estas ligações complementam atividades de P\&D internas às empresas, que são consideradas o principal fator de acesso das PEs à fontes tecnológicas externas.

Este resultado não é corroborado pelas informaçōes oriundas da base de dados do CIS3 e pela PINTEC. ${ }^{11}$ Constatou-se, nestas pesquisas, que as relações estabelecidas pelas empresas com universidades e centros de pesquisa estão diretamente relacionadas ao tamanho - uma maior proporção de grandes empresas estabelece arranjos de cooperação com estas instituições.

Como as pesquisas em consideração não têm metodologias comuns e foram realizadas em momentos diferentes, é necessário certa cautela com as conclusões oriundas das mesmas.

Uma segunda hipótese usualmente apontada como importante para explicar a significativa participação das PEs na inovação em alguns setores diz respeito à maior flexibilidade organizacional encontrada nessas empresas. Vale dizer, a presença de menos níveis hierárquicos e de estruturas menos burocratizadas facilitam a tomada de decisões e as alterações no processo produtivo, constituindo importantes elementos a favorecer a atividade de inovação (OECD, 1993).

Entretanto, a flexibilidade como característica intrínseca às PEs merece algumas qualificações. Em primeiro lugar, os aspectos acima apontados não são os únicos a conferir flexibilidade às PEs que, freqüentemente, decorre de "fatores menos nobres". Pode-se citar, como exemplos, a falta de planejamento e a não observância de direitos trabalhistas como fatores determinantes de flexibilidade (Souza, 1995).

Segundo, seguindo a proposta de Carlsson (1989), é possível diferenciar os diversos tipos de flexibilidade encontrados no interior da empresa. $\mathrm{O}$ autor propõe resumi-las em flexibilidade operacional, tática e estratégica. As flexibilidades operacional e tática referem-se às rotinas de curto prazo das empresas. Define-se, no primeiro caso, pela capacidade da empresa de alterar a seqüência e os procedimentos usuais de produção (alterações no software). A

\footnotetext{
11 Pesquisa de Inovação Tecnológica $(2000,2003)$ realizada pela FINEP, MCT, IBGE e MPOG. Disponível em www.ibge.gov.br.
} 
flexibilidade tática refere-se à tecnologia utilizada, em termos das possibilidades de alterar quantidade produzida, o mix de produtos e certas características do design. Ressalte-se que a flexibilidade tática, em função de diferenças setoriais, nem sempre se coloca para a empresa como uma opção. A flexibilidade estratégica, ou dinâmica, diz respeito à capacidade da empresa de planejar e atuar de modo a se inserir futuramente no mercado, o que envolve esforços constantes em qualidade e qualificação de pessoal de modo a promover inovação de produtos e/ou processos.

A consideração dos diferentes aspectos atinentes à noção de flexibilidade determina a necessidade de qualificar a relação entre flexibilidade e inovação em PEs. Assim, a presença de menores níveis hierárquicos e menor burocracia em conjunto com a qualificação ampla da mão-de-obra e/ou da gerência - que engloba a capacidade de estabelecer relações com fontes externas de tecnologia - são os elementos principais a conferir flexibilidade estratégica às PEs.

A hipótese da flexibilidade organizacional como fator determinante da inovação em PEs é um dos elementos que sustentam o modelo de "especialização flexível” (EF) (Piore \& Sabel, 1984). Grosso modo, o modelo de EF advoga a existência de uma crise no paradigma fordista de acumulação, baseado na produção em massa, e a sua superação pela utilização de métodos flexíveis de produção. ${ }^{12}$ A produção capitalista, sob a égide do modelo de EF, contrapóe-se às rigidities fordistas e caracteriza-se pela flexibilidade derivada da utilização de tecnologias de base microeletrônica (máquinas multipropósitos) e trabalhadores polivalentes (com múltiplas qualificações), o que propicia produções diversificadas. A presença nas empresas de trabalhadores multiqualificados e aptos a intervir na totalidade do processo de produção, bem como os menores níveis hierárquicos, conferem maior flexibilidade ao processo produtivo na medida em que rompem com a tradicional separação entre trabalho de concepção e de execução. Estes fatores potencializam a atividade de inovação na medida em que esta não se restringe mais a um departamento da empresa.

Outro aspecto a conferir graus mais elevados de flexibilidade às empresas, tratado por Piore e Sabel, respeita ao processo de desverticalizaçao pelo

\footnotetext{
12 Por fugir ao escopo deste trabalho, não se fará referência aos debates que cercaram a difusão da tese central do trabalho de Piore \& Sabel (1984).
} 
qual passaram principalmente as grandes empresas e que propiciaram, em alguns casos, relações de parceria com PEs, por meio de mecanismos de subcontratação (segundo os modelos de redes, presentes, sobretudo, na região alemã do Baden-Württemberg e nas indústrias de montagem japonesas). Neste formato organizacional, há espaço para relações empresariais mais estáveis e menos assimétricas entre grandes e pequenas empresas, quando de fato se busca a flexibilidade advinda da maior especialização produtiva.

A flexibilidade organizacional - especialmente quando determinada por trabalhadores com "funções múltiplas" (possibilitadas, principalmente, pela utilização de técnicas mais simples de produção nas empresas de pequeno porte), por limites difusos entre trabalho de concepção e de execução e por maior especialização - sempre foi considerada uma característica das PEs. Esta característica é considerada por Piore e Sabel o fator principal de alguns resultados positivos alcançados pelas PEs nas últimas décadas. Destaque-se, em especial, a participação significativa de PEs na inovação em alguns setores industriais e a presença importante, em termos do desenvolvimento econômico, de PEs em aglomerações, igualmente pautados pela busca da inovação.

É importante mencionar ainda que a chamada teoria do ciclo de vida do produto, desenvolvida por Vernon na década de 1960, também trata da relação entre PEs e inovação. Em linhas gerais, esta teoria advoga que as PEs empreendem as inovações radicais e têm algumas vantagens durante os estágios iniciais no ciclo de vida de um produto, quando este ainda é produzido em pequenas quantidades e com técnicas mais rudimentares. À medida que o processo de produção vai sendo padronizado, as GEs apresentam vantagens competitivas derivadas, principalmente, de economias de escala.

A análise sobre o processo de desenvolvimento de inúmeros produtos industriais nas últimas duas décadas permite questionar o status teórico da contribuição de Vernon (Sabel et al., 1991). Embora a presença de fases no ciclo de vida do produto seja aplicável à parcela importante dos produtos industriais, não engloba inúmeros exemplos onde o ciclo de vida do produto é realizado na sua totalidade em PEs (bens de capital sob encomenda, produtos com requerimentos específicos, etc.) ou em GEs (produtos de processamento contínuo, os bens da indústria automobilística, a grande maioria dos bens do setor eletrônico, etc.). As empresas tipicamente fordistas que entraram em 
processo de decadência e perderam competitividade para outras (muitas vezes de menor tamanho) que aplicaram métodos mais flexíveis de produção também se contrapõem à tese do ciclo de vida do produto. ${ }^{13}$

A maior participação das PEs nas fases iniciais do desenvolvimento de novos produtos é uma das conclusões do trabalho de Utterback (1994). Uma análise ampla da dinâmica da inovação - estudo de produtos e processos inovadores desde o protótipo até o projeto dominante - permite ao autor concluir que a participação de empresas novas na inovação é maior nas indústrias de produtos montados (em relação aos não-montados ou de processamento contínuo). Nas indústrias de produtos montados, a participação de empresas novas e menores vai diminuindo à medida que as inovações vão sendo introduzidas e aceitas. A partir daí, há uma diminuição do número de empresas e aumento do seu tamanho médio e as inovaçōes de processo (incrementais) ganham espaço na competição.

Em síntese, a presença de PEs inovadoras na estrutura industrial está relacionada com as seguintes condiçōes (OECD, 1993; Pavitt, 1992; Rizzoni, 1994; Utterback, 1994):

i) existência de atividades próprias de $\mathrm{P} \& \mathrm{D}$ (formais ou informais) e/ou de relaçôes estreitas com fontes externas de conhecimento tecnológico (universidades, centros de pesquisa e/ou de difusão tecnológica, outras empresas);

ii) presença de mão-de-obra qualificada (em nível da propriedade/gerência e/ou do pessoal de nível técnico) e apta a estabelecer relações com fontes externas de tecnologia;

iii) flexibilidade estratégica determinada por alta qualificação da mão-deobra e menos hierarquia, tornando a empresa apta a explorar novas oportunidades;

iv) o setor em que a PE está inserida (setores com altas oportunidades tecnológicas ou aqueles que requerem proximidade com clientes, por exemplo);

13 O modelo de ciclo de vida do produto é utilizado no trabalho de Storey \& Tether (1998) para avaliar positivamente as políticas que objetivam a criação de new technology-based firms, em função da contribuição que essas empresas podem apresentar na transformação da estrutura industrial rumo à fronteira do desenvolvimento tecnológico. Entretanto, os autores ressaltam as dificuldades intrínsecas à generalização do modelo e o utilizam como recurso analítico (ou, "interpretação otimista" do modelo, dado que permite realçar o papel das PEs na mudança estrutural). 
v) a fase do desenvolvimento do produto;

vi) o ambiente no qual a empresa opera: condições macroeconômicas adequadas, disponibilidade de financiamento, mecanismos de difusão tecnológica, políticas de incentivo à formação de parcerias com grandes empresas e outras instituições, etc.

A análise destes aspectos tem indicado, entre outros, a importância da localização geográfica para a atividade de inovação, em especial em setores de tecnologia de ponta. Considerando a natureza parcialmente tácita do conhecimento, verifica-se que as interações entre instituições geradoras de conhecimento e empresas apresentam-se mais promissoras quando há proximidade geográfica, de modo a viabilizar que os spillovers da pesquisa acadêmica gerem mais rapidamente atividades produtivas. ${ }^{14}$

Como mostram Galli e Teubal, diversas ações nesse sentido têm sido instituídas:

“...os fatos mais notáveis dizem respeito à proliferação de organizaçôes, agências e outras estruturas ligadas à inovação e à reestruturação econômica em nivel regional. O objetivo dessas estruturas é induzir a mudança da estrutura industrial para atividades intensivas em conhecimento. Elas incluem diferentes categorias de iniciativas, tais como centros de tecnologia, centros de inovação, science parks, incubadoras (ou outros com denominação similar) direcionadas a suprir consultoria técnica, financeira e comercial aos empresários locais." (1997:351)

As iniciativas assinaladas por Galli e Teubal estão fundamentadas no entendimento de que é possível potencializar a atividade inovativa e superar determinadas debilidades das pequenas empresas em setores de tecnologia de ponta por meio de vínculos mais consistentes com instituições de ensino/ pesquisa, especialmente os públicos. O estímulo a esses vínculos apresenta-se

14 O trabalho de Baptista \& Swann (1998), também utilizando a base de dados do SPRU, tenta responder à questão se a atividade de inovação tende a ser maior em clusters. O cruzamento desses dados com os devidos recortes regionais demonstrou que a probabilidade de inovação é maior nas localidades onde é forte a presença de firmas da própria indústria, ou seja, nos clusters ou aglomerações. 
mais promissor em localidades onde é possível criar e/ou desenvolver aglomerações empresariais setoriais que, para o caso de empresas na fronteira tecnológica, requerem a presença de instituições de pesquisa com tradição em pesquisa aplicada. ${ }^{15}$

A despeito da ocorrência de um grande número de iniciativas visando o estímulo às parcerias universidade-indústria, os resultados apresentados na CIS3, bem como na PINTEC $(2000,2003)$, indicam um baixo grau de interação entre as pequenas empresas inovadoras e universidades e centros de pesquisa em torno de 5\% para as empresas européias e $4 \%$ para as brasileiras. Estes resultados não são uniformes entre países - dentre os países da OECD o percentual situa-se em torno de 10\% (Cassiolato et al., 2005).

Portanto, ainda é reduzido o número de empresas que estabelecem interações com universidades e centros de pesquisa, apesar de algumas diferenças setoriais e entre países. Entretanto, estas interações apresentam-se tendencialmente crescentes na medida em que, nas últimas décadas, este é um dos focos principais das políticas industriais vigentes em países desenvolvidos e em desenvolvimento (OECD, 1999).

Tomando como referência os aspectos teórico-conceituais oriundos da revisão da experiência internacional, é possível identificar um perfil de PEs presentes em setores de tecnologia avançada. Em geral, são empresas que realizam atividades internas de $\mathrm{P} \& \mathrm{D}$, mesmo que informalmente, que são complementadas com fontes externas de tecnologia. A presença de pessoal qualificado, em nível da gerência e/ou quadro técnico, garante o estabelecimento de interações com fontes externas de tecnologia, interaçõos estas que tendem a ser mais facilmente obtidas em aglomerações de empresas, dada a maior facilidade de difusão do conhecimento que tem lugar nestas estruturas.

A análise dos resultados obtidos em pesquisa de campo recente em empresas de pequeno porte presentes em aglomeraçôes no Estado de Minas Gerais encontrou semelhante perfil de empresas. As duas seções seguintes são dedicadas à análise dos resultados desta pesquisa. Um breve histórico da formação dessas aglomerações também é apresentado nas seções correspondentes, de

15 Ver OECD (1999), para um tratamento exaustivo dessa temática. O documento aborda diversas experiências nacionais de aglomerações, bem como diversos formatos organizacionais, considerando a atividade de inovação como o eixo norteador tanto das análises, como da intervenção política. 
modo a ressaltar o papel das instituições de ensino/pesquisa presentes, que atuam como importantes fontes externas de tecnologia.

\section{Interação universidade/empresa e inovação no arranjo produtivo de eletrônica e telecomunicações de Santa Rita do Sapucaí}

O surgimento dessa aglomeração ${ }^{16}$ esteve atrelado principalmente à criação da Escola Técnica de Eletrônica (ETE), em 1958, por iniciativa de Luzia Rennó Moreira que, dotada de visão schumpeteriana, tencionava deslocar a vocação agrário-pastoril de Santa Rita do Sapucaí para a área de eletrônica, considerada um segmento industrial promissor àquela época, na qual estava constituindo-se a indústria nacional de eletrônica e comunicações (Diniz \& Lemos, 1998).

Nesse contexto, o objetivo da ETE era proporcionar a formação e capacitação de mão-de-obra especializada, capaz de suprir a demanda desse mercado em expansão. Posteriormente, foram fundados no município o Instituto Nacional de Telecomunicaçôes (INATEL) em 1965, um instituto voltado à pesquisa e ensino de graduação e pós-graduação em Engenharia Elétrica e Telecomunicações, e a Faculdade de Administração e Informática (FAI) em 1972, que motivaram algumas experiências informais de incubação de empresas entre as décadas de 1970 e 1980 em Santa Rita, estimulando a especialização nos setores de eletrônica e telecomunicações.

Em 1985, o poder municipal juntamente com algumas lideranças locais cria o slogan "Vale da Eletrônica" (em referência ao Vale do Sićlio, nos EUA), com o intuito de incentivar as empresas existentes e estimular novas empresas por meio de políticas direcionadas que, juntamente com o surgimento de programas de incubação de empresas, foram responsáveis pela governança do arranjo. Neste sentido, merecem destaque a atuação da Incubadora de Empresas do INATEL, fundada oficialmente em 1992 e da Incubadora Municipal de Empresas Sinhá Moreira, criada em 1999.

Atualmente, além das instituições de ensino e pesquisa mencionadas, o APL conta com um consórcio de exportação formado por seis empresas (de

16 No Brasil, tem se difundido o termo arranjo produtivo local (APL) para a referência a "aglomerações produtivas cujas interações entre os agentes não são suficientemente desenvolvidas para caracterizá-las como sistemas." (Cassiolato \& Szapiro, 2002:12). Utilizar-se-á este termo como sinônimo de aglomerações produtivas. 
produtos não concorrentes), que exportam para México, Chile, Bolívia e Cuba, ${ }^{17}$ duas incubadoras de empresas (INATEL e Incubadora Municipal Sinhá Moreira), Associação Comercial, Associação Industrial, um sindicato patronal (SINDVEL), SESI, SENAI, balcão SEBRAE, Prefeitura Municipal e três instituições de apoio financeiro às empresas (Banco de Desenvolvimento de Minas Gerais, Banco do Brasil e Caixa Econômica Federal). Além disso, existe em Santa Rita um projeto de cooperação técnica internacional feito em parceria com as Agências de Cooperação Técnica dos governos alemão e brasileiro (GTZ e ABC, respectivamente), beneficiando as escolas INATEL, FAI, ETE, Colégio Tecnológico Dr. Delfim Moreira (cursos técnicos de informática e contabilidade), empresas industriais locais e poder municipal (INATEL, 2004).

Uma característica marcante do APL de Santa Rita do Sapucaí é a articulação existente entre empresas, centros de ensino e pesquisa (principalmente ETE e INATEL), incubadoras de empresas (INATEL e Incubadora Municipal) e a Prefeitura Municipal, o que possibilita o compartilhamento e transmissão de conhecimentos entre esses agentes. Em menor medida, há alguma influência das associações empresariais locais (Consórcio de Exportação, Associação Industrial, Associação Comercial e SINDVEL) e instituições de apoio às empresas (SEBRAE, ${ }^{18}$ SESI, SENAI) sobre a governança do arranjo. Entretanto, há que se destacar a ausência de alguns elos da cadeia produtiva eletroeletrônica (fornecedores de insumos e de máquinas e equipamentos, por exemplo) e seus efeitos sobre a dinâmica do arranjo, o que desautoriza caracterizar essa aglomeração produtiva como sendo um sistema produtivo local. ${ }^{19}$

A significativa influência das instituições de ensino e pesquisa na governança do arranjo se expressa em um alto percentual de empresas que surgiram como spin-offs das atividades acadêmicas. Em consonância com esse resultado, verificou-se a ocorrência de uma proporção elevada de empresários com curso superior completo - $32 \%$ nas microempresas, $35,7 \%$ nas pequenas e $75 \%$ nas

17 Dentre os produtos fabricados (existentes no mercado nacional) e exportados, estão: equipamentos de radiodifusão, radiocomunicação, centrais telefônicas, terminais de consulta ao crédito, fontes de alimentação e transformadores, identificadores e bloqueadores de chamadas e transmissores FM de baixa potência.

18 Verificou-se na pesquisa de campo, que a atuação do balcão SEBRAE em Santa Rita têm sido mais no sentido de fornecer alguns cursos e treinamentos "rápidos" e de alguma interação junto à Incubadora Municipal.

19 Sistemas Produtivos Locais são "... aglomerados de agentes econômicos, políticos e sociais, localizados em um mesmo território, que apresentam vínculos consistentes de articulação, interação, cooperação e aprendizagem voltadas à introdução de novos produtos e processos." (Cassiolato \& Szapiro, 2002:12). 
médias empresas - bem como de trabalhadores com graus de escolaridade superiores aos verificados entre o conjunto das empresas de pequeno porte brasileiras.

A partir da pesquisa de campo realizada em Santa Rita do Sapucaí em meados de 2003 constatou-se que, nesse ano, o município abrangia aproximadamente 80 empresas de base tecnológica, especializadas nos segmentos de eletrônica, telequipamentos e informática, que geravam 5.600 empregos diretos e indiretos ${ }^{20}$ segundo fontes locais, em contraste com os dados do Relatório Anual de Informações Sociais (RAIS) que, em 2002, acusava 56 empresas formalmente constituídas e 1.218 empregados (Tabela 2). ${ }^{21}$

\section{TABELA 2}

Número de empregados e de empresas da indústria do material elétrico e comunicações em Santa Rita do Sapucaí/MG, 1990, 1994, 1997, 2001, 2002

\begin{tabular}{lcccccc}
\hline & \multicolumn{2}{c}{ Micro } & \multicolumn{2}{c}{ Pequena } & \multicolumn{2}{c}{ Média } \\
Anos & $\mathrm{N}^{\circ}$ Empresas & $\mathrm{N}^{\circ}$ Empregos & $\mathrm{N}^{\circ}$ Empresas & $\mathrm{N}^{\circ}$ Empregos & $\mathrm{N}^{\circ}$ Empresas & $\mathrm{N}^{\circ}$ Empregos \\
1990 & 15 & 98 & 7 & 410 & 3 & 440 \\
1994 & 15 & 132 & 8 & 382 & 3 & 393 \\
1997 & 27 & 178 & 8 & 327 & 1 & 411 \\
2001 & 43 & 204 & 11 & 519 & 2 & 238 \\
2002 & 41 & 215 & 13 & 645 & 2 & 358 \\
\hline
\end{tabular}

Fonte: RAIS/MTE (1990, 1994, 1997, 2001, 2002).

20 Informações obtidas junto à Prefeitura Municipal, Associação Industrial e Sindicato de Indústrias de Aparelhos Eletrônicos e Similares (SINDVEL) em 2003. O cálculo da amostra de empresas entrevistadas procurou refletir a representatividade do porte das empresas de acordo com a classificação do SEBRAE, a saber: microempresa, de 0 a 19 empregados; pequena empresa, de 20 a 99; média empresa, de 100 a 499 e grande empresa, acima de 500 empregados. Para o cálculo da amostra foi considerada uma população de 80 empresas, o que resultou em uma amostra de mais de $50 \%$ das empresas, considerando as informações obtidas junto às instituições locais, e de mais de $70 \%$, considerando os dados da RAIS

21 Apesar de já estarem disponíveis os dados da RAIS para 2003-2005, optou-se por não atualizá-los neste trabaIho, uma vez que os dados de 2002 foram os utilizados para calcular a amostra de empresas da pesquisa de campo. Ademais, como a pesquisa foi realizada em 2003, todas as informações aqui apresentadas referem-se a esse período. 
Tomando como base os cruzamentos de informações relativas ao número de empresas, foram entrevistadas no arranjo 43 empresas, que compuseram uma amostra com micro, pequenas e médias empresas.

\subsection{Interações entre agentes, aprendizado e inovações}

A pesquisa realizada em Santa Rita do Sapucaí investigou a ocorrência de inovaçôes no período 2000-2002, bem como as fontes de aprendizado consideradas relevantes para a atividade inovativa no período. Levando-se em conta o processo de geração de inovações com base apenas em gastos de $\mathrm{P} \& \mathrm{D}$, as firmas captadas na amostra da pesquisa de campo mostraram-se altamente inovadoras. Entre os anos de 2000 e 2002, a maior parte das empresas entrevistadas (30 empresas) desenvolveram atividades de pesquisa e desenvolvimento ( $P \& D)$ rotineiramente, contra sete que desenvolveram ocasionalmente e apenas cinco que não investiram nesse tipo de atividade nos três anos em consideração. Quanto à porcentagem de gastos em $\mathrm{P} \& \mathrm{D}$ em relação ao faturamento no último ano (Tabela 3), em média, as microempresas responderam ter investido $10 \%$, as pequenas $7 \%$ e as empresas de porte médio 3,1\%. Os percentuais são bastante elevados, tomando-se como referência outros

TABELA 3

Gastos com P\&D, em relação ao faturamento de 2002

\begin{tabular}{|c|c|c|c|c|}
\hline & Micro (\%) & Pequena (\%) & Média (\%) & Grande (\%) \\
\hline 1. Gastos com P\&D/total (\%) & 10 & 7 & 3,1 & - \\
\hline 2. Gastos com atividades inovativas & 11,9 & 12,5 & 2,8 & - \\
\hline \multicolumn{5}{|l|}{ 3. Fontes de financiamento } \\
\hline 3.1. Próprios & 88,6 & 92,3 & 79,2 & - \\
\hline 3.3. Terceiros privado & - & 3,8 & 20,8 & - \\
\hline 3.3. Terceiros público & 11,4 & 3,8 & - & - \\
\hline Total (\%) & 100 & 100 & 100 & - \\
\hline
\end{tabular}

Fonte: pesquisa de campo (2003). 
estudos e aqueles divulgados no âmbito da PINTEC (2003), em que as empresas com atividades inovativas relataram gastos totais de $2,5 \%$ do faturamento, em média, e gastos com P\&D interno de $0,53 \%$ do faturamento. Outro aspecto importante com referência às informaçôes da Tabela 2 , diz respeito à pequena participação de recursos de terceiros no financiamento das atividades de inovação, expressão de uma dificuldade intrínseca à economia brasileira e divulgada em diversos estudos.

Como pode ser visto na Tabela 4, a maioria das empresas entrevistadas desenvolveu algum tipo de inovação de produto no último triênio - $64 \%$ das microempresas, $78,6 \%$ das pequenas empresas e $100 \%$ das empresas de porte médio. A título de comparação, a PINTEC (2000) identificou, dentre as 70.000 empresas industriais com mais de dez empregados entrevistadas que 31,5\%, em média, implementaram inovaçóes, de produto, processo ou ambas. Esse percentual cai para 26,6\% para empresas que empregam de 10 a 49 empregados. Para a indústria eletrônica, a PINTEC detectou uma taxa de inovação bastante superior, de 62,5\%, mas mesmo assim inferior às detectadas pela pesquisa de campo em Santa Rita do Sapucaí. ${ }^{22}$

Destaque-se ainda que para as inovações de processo, organizacionais e outras também foram encontrados percentuais elevados de respostas positivas (sempre superiores a $50 \%$ das empresas entrevistadas).

Com relação ao tipo de inovação, os dados coletados na pesquisa mostram que um percentual muito significativo de empresas (28\% das micro, $50 \%$ das pequenas e $75 \%$ das médias) afirmou ter desenvolvido produtos novos para o mercado nacional, enquanto $12,5 \%$ das microempresas, $21,4 \%$ das pequenas e $24 \%$ das médias afirmou ter desenvolvido produtos novos para o mercado internacional. Em que pese algum tipo de entendimento equivocado por parte dos empresários quanto ao questionamento em tela, os percentuais são significativamente altos tendo como referência os encontrados no âmbito da PINTEC e de outras pesquisas recentes sobre o tema.

22 A PINTEC (2003) apresentou resultados um pouco superiores - 33,3\% das empresas empreenderam algum tipo de inovação no período analisado (2001-2003). Também aumentou, para 31,1\%, a taxa de inovação dentre as empresas que possuem de dez a 49 empregados. Entretanto, para a indústria eletrônica detectou-se queda na taxa de inovação, dado que $56,7 \%$ das empresas informaram a realização de algum tipo de inovação no período. Destaque-se que os resultados setoriais da PINTEC não estão disponíveis segundo a classificação de porte das empresas. 
TABELA 4

Inovações entre 2000 e 2002, Santa Rita do Sapucaí (MG)

\begin{tabular}{|c|c|c|c|}
\hline Tipo de inovação & $\begin{array}{l}\text { Micro } \\
\text { Sim (\%) }\end{array}$ & $\begin{array}{l}\text { Pequena } \\
\text { Sim (\%) }\end{array}$ & $\begin{array}{l}\text { Média } \\
\text { Sim (\%) }\end{array}$ \\
\hline 1. Inovações de produto & 64 & 78,6 & 100 \\
\hline $\begin{array}{l}\text { 1.1. Produto novo para a empresa, mas já existente } \\
\text { no mercado }\end{array}$ & 52 & 57,1 & 75 \\
\hline 1.2. Produto novo para o mercado nacional & 28 & 50 & 75 \\
\hline 1.3. Produto novo para o mercado internacional & 12 & 21,4 & 25 \\
\hline
\end{tabular}

\section{Inovações de processo}

2.1. Processos tecnológicos novos para a empresa, 
Considerando a importância das diferentes fontes de informação determinantes dos processos de aprendizado e geração de inovações, investigou-se a importância atribuída pelas empresas a cada uma delas (Tabela 5). Constatou-se que a principal fonte interna de informação para o aprendizado das microempresas entre 2000 e 2002, por grau de importância, foi o departamento de P\&D ou pessoal ocupado envolvido diretamente com P\&D (índice de 0,85 ) e citado por 21 dentre as 25 microempresas entrevistadas. Importância maior às atividades de $\mathrm{P} \& \mathrm{D}$ foi atribuída pelas médias empresas da amostra, com índice de 1,00, o mesmo índice atribuído às demais fontes internas de informação. Dentre as pequenas empresas, o maior índice encontrado foi para a área de produção $(0,83)$. A relevância das atividades de $\mathrm{P} \& \mathrm{D}$ para a maior parte das empresas do APL está relacionada ao perfil da área de eletrônica, cuja competitividade depende significativamente da busca constante de informações.

Quanto às fontes externas de informação, atribuiu-se importância por parte das empresas principalmente aos itens fornecedores de insumos (índices de 0,51 a 0,80 ), clientes (índices entre 0,73 a 0,90 ), concorrentes (índices de 0,74 e 0,75 para micro e médias empresas) e outras empresas do setor (índice de 0,80 para as médias empresas). Já os itens "outras empresas do grupo" e “joint-ventures” foram assinalados somente pelas médias empresas, em acordo com as características desse tipo de relação.

No que concerne ao aprendizado decorrente do contato com universidades e outros institutos de pesquisa no último triênio, as empresas atribuíram os níveis mais elevados de importância às relações com universidades, com índices de relevância de 0,60,0,53 e 0,80, respectivamente para micro, pequenas e médias empresas da amostra (68\% das microempresas, $57 \%$ das pequenas e $100 \%$ das médias atribuíram média e alta importância a esse tipo de relação). Considerou-se, em especial, o INATEL, cuja interação com as empresas se dá por meio de desenvolvimento de produtos, consultorias, utilização de laboratórios, etc. Constatou-se na pesquisa de campo que a ETE e o INATEL são as instituições locais de ensino e pesquisa que mais exercem influência sobre as empresas do arranjo, no sentido de fornecer pessoal qualificado (em nível de $2^{\circ}$ grau técnico em eletrônica industrial/telecomunicações/informática, no caso da ETE e, no caso do INATEL, em nível de 
TABELA 5

Caracterização da amostra de micro, pequenas e médias empresas de eletrônica, informática e telecomunicações em Santa Rita do Sapucaí-MG, quanto à importância das fontes de informação, 2000-2002

\begin{tabular}{lccc}
\hline Descrição & $\begin{array}{c}\text { Micro } \\
\text { Índice de } \\
\text { Relevância* }\end{array}$ & $\begin{array}{c}\text { Pequena } \\
\text { Índice de } \\
\text { Relevância* }\end{array}$ & $\begin{array}{c}\text { Média } \\
\text { Índice de } \\
\text { Relevância* }\end{array}$ \\
Fontes internas & & 0,49 & 1,00 \\
Departamento de P\&"D & 0,85 & 0,83 & 1,00 \\
Área de produção & 0,46 & 0,75 & 1,00 \\
Áreas de vendas e marketing & 0,65 & 0,68 & 1,00 \\
Serviços de atendimento ao cliente & 0,65 & 0,00 & 0,25 \\
Outras & 0,00 & &
\end{tabular}

\section{Fontes externas}

Outras empresas dentro do grupo

0,00

Empresas associadas (joint venture)

Fornecedores de insumos (equipamentos, materiais)

Concorrentes

Outras empresas do setor

\section{Universidades e outros institutos de pesquisa}

Universidades

Centros de capacitação profissional, de assistência

\section{Outras fontes de informação}

Licenças, patentes e know-how

$\begin{array}{lll}0,30 & 0,39 & 0,00 \\ 0,72 & 0,61 & 0,90 \\ 0,81 & 0,74 & 0,90 \\ 0,40 & 0,37 & 0,70\end{array}$

Associações empresariais locais (inclusive consórcios 
graduação e pós-graduação em telecomunicações), interagindo também com outros agentes, como por exemplo, na parceria com a Incubadora Municipal de empresas (prestação de consultoria técnica). Além disso, o acesso de exalunos (atualmente empresários e/ou funcionários de empresas do arranjo) aos laboratórios e serviços técnicos dessas instituições também garante um fluxo contínuo de informações e conhecimentos que são compartilhados por esses agentes, gerando externalidades ao APL de modo geral. ${ }^{23}$

Verificou-se, por fim, que em relação ao aprendizado adquirido por meio de outras fontes de informação, todos os itens citados na pesquisa mereceram atribuição de alta e média importância por parte de todos os portes de empresa, com exceção dos itens "encontros de lazer" e "licenças, patentes e knowhow". O destaque maior foi a alta importância atribuída às fontes de informação disponíveis na "internet", bem como em "feiras, exibições e lojas", "conferências, seminários, cursos e publicações especializadas" para microempresas (índices entre 0,74 e 0,90). As empresas de porte médio, por sua vez, atribuíram alta importância a praticamente todos os itens mencionados na questão. Merece registro que a principal localização dessas fontes de informação para todos os portes de empresa encontra-se em âmbito nacional, sendo que as médias empresas também destacaram participar de feiras e exposições ocorridas no exterior.

Constatou-se que para as empresas industriais que atuam na fabricação e/ou montagem de aparelhos e equipamentos eletroeletrônicos e de telecomunicações, a busca e seleção de inovações são processos desenvolvidos freqüentemente, sem os quais as firmas não conseguem se manter competitivas no mercado de atuação. Por outro lado, empresas voltadas à fabricação e/ou montagem de placas, fabricação de transformadores, etc. ou ainda especializadas em prestação de serviços em telefonia (instalação, manutenção, etc.) e em desenvolvimento de software e alguns tipos de projetos industriais, praticamente não há espaço para inovações por iniciativa das empresas, pois tais produtos e/ou serviços são predeterminados de acordo com os clientes. Algumas empresas mencionaram ter realizado inovaçōes incrementais em

23 Na pesquisa de campo, alguns empresários entrevistados destacaram a importância das parcerias entre o INATEL e suas empresas no desenvolvimento de novos produtos, dentre eles, o caso da TV digital envolvendo a Linear (empresa pioneira no arranjo) e esse instituto. 
equipamentos de segurança (cercas elétricas, sensores, centrais de alarmes, etc.); automação industrial (sistemas de monitoramento), equipamentos eletrônicos (aperfeiçoamento de microcâmeras, por exemplo), dentre outros.

Como exemplos de inovações desenvolvidas por algumas empresas entrevistadas, incluem-se: fabricação nacional de rádios digitais; transmissor de microondas (produto novo para o mercado internacional); aparelhos com funções de interfone e telefone; tele-supervisão para ambientes indoor de celular; leitor de código de barras sem fio; aparelho controlador de tarifas telefônicas; dentre outros. Estes exemplos foram classificados pelas empresas entrevistadas como inovações radicais empreendidas por elas. Como apenas um deles foi citado como inovação para o mercado internacional, é mais prudente considerar tais inovações como incrementais, com a sua devida importância, dado que se tratam de produtos inexistentes no mercado nacional e/ou que passaram por expressivas transformaçōes.

Em termos de inovações de processo, houve uma empresa especializada em segurança eletrônica, que mencionou ter desenvolvido e lançado no setor um processo tecnológico novo (um tipo de comunicação que não existia antes) em um aparelho destinado à automação industrial. De acordo com as empresas entrevistadas, alguns produtos inovadores já se encontram no mercado e outros ainda estão sendo testados e aperfeiçoados para serem lançados futuramente.

Em suma, verificou-se que em Santa Rita do Sapucaí as parcerias estabelecidas entre empresas, instituições de ensino/pesquisa e poder público municipal têm desempenhado um papel importante na consolidação e expansão do APL de eletrônica e telecomunicaçóes, pois, dentre outros elementos, proporcionam um ambiente favorável à criação de novas empresas e no estímulo à capacidade inovativa desses agentes. Para as empresas de base tecnológica existentes no município, a proximidade não apenas geográfica com a ETE e o INATEL tem sido possível graças aos objetivos dessas instituições de ensino e pesquisa em proporcionar mão-de-obra qualificada e especializada nos diversos segmentos de eletrônica, informática e telecomunicações, favorecendo significativamente as empresas do arranjo, que também se beneficiam do acesso aos laboratórios e serviços disponibilizados por essas escolas. Em especial, a interação entre empresas e centros de ensino e pesquisa (na forma de incubadoras de empresas) vem determinando externalidades positivas. Na pesquisa 
realizada, as empresas atribuíram importância maior aos fatores locacionais "qualidade da mão-de-obra”, "custo da mão-de-obra” (devido serem mais baixos que em cidades maiores onde estão localizadas a maior parte das empresas deste setor) e "proximidade com universidades/centros de pesquisa".

Portanto, as respostas dadas pelas empresas indicam que no APL o processo de difusão de informações é intenso, fruto do direcionamento das atividades produtivas e de esforços político-institucionais para o a criação e fortalecimento de uma "vocação" no município.

\section{Interação universidade/empresa e inovação no arranjo produtivo de biotecnologia de Belo Horizonte (MG)}

O desenvolvimento de atividades produtivas ligadas à chamada bioindústria é bastante recente no Brasil, em torno de duas décadas. Contabiliza-se atualmente cerca de 300 empresas identificadas como de biotecnologia, sendo que pouco mais de $80 \%$ estão instaladas nos estados de São Paulo, Rio de Janeiro e Minas Gerais. Nesse último estado, encontra-se a maior aglomeração de empresas desse ramo de atividade, concentradas na capital Belo Horizonte (BIOMINAS, 2001).

A aglomeração de empresas de biotecnologia ${ }^{24}$ em Belo Horizonte devese, entre outros fatores que historicamente favorecem a região, ao estoque de conhecimento gerado pela Universidade Federal de Minas Gerais (UFMG) e outras instituições de pesquisa que se destacam fortemente nas áreas de biologia, medicina, farmácia, química, veterinária, o que resulta em uma grande concentração de competências científicas na capital. Além disso, Belo Horizonte conta, desde 1990, com a Fundação Biominas, a primeira incubadora de empresas de biotecnologia construída no país.

A Biominas é uma instituição privada, sem fins lucrativos, criada em

24 Não há uma definição única para o termo biotecnologia. No Brasil, o Sindicato das Empresas de Biotecnologia (SindBio), adota a mesma definição utilizada pelas organizações internacionais FAO e OECD, ou seja, "biotecnologia é a aplicação de sistemas biológicos e organismos vivos para a criação de produtos". É um conceito mais restrito. A Fundação Biominas, por sua vez, assume uma definição mais ampla, qual seja, é "a aplicação de diversas tecnologias 'habilitadoras', envolvendo organismos vivos, células ou moléculas para a geração de produtos e serviços, tendo, numa visão de 'cadeia produtiva', incorporado também empresas fornecedoras de equipamentos e insumos industriais utilizados e empresas atuantes em áreas de sinergia e afinidade (biomedicina, biomateriais, aplicações integradas de IT, software, internet)". Utilizar-se-á essa definição no presente trabalho. 
1990 em Belo Horizonte por meio da ação de nove micro e pequenas empresas de biotecnologia, com o objetivo de apoiar e ampliar a bioindústria no estado. É a gestora/fundadora da Incubadora de Empresas de Biotecnologia e Química Fina de Minas Gerais - IEB-MG, que foi implantada em 1996. Até então, as novas empresas se constituíam por meio do apoio institucional e gerencial da Fundação Biominas, surgindo assim como incubadas virtuais.

Em 1991, os governos estadual e municipal, a Universidade Federal de Minas Gerais (UFMG) e a Fundação Biominas assinaram um Protocolo de Intenções que resultou fundamentalmente na conclusão da construção das instalações da IEB-MG, em 1996. Além disso, também houve o apoio financeiro e técnico-gerencial de instituições como a Financiadora de Estudos e Projetos (FINEP) e o Serviço Brasileiro de Apoio às Micro e Pequenas Empresas (SEBRAE). O intuito do protocolo era desenvolver mecanismos e compromissos institucionais capazes de contribuir na formulação do projeto e no plano de implantação da incubadora. No ano seguinte, as partes envolvidas formalizaram um Convênio de Cooperação, estabelecendo as suas responsabilidades na criação e operacionalização da mesma (Lemos, 1998).

Desde então, o que se pode verificar é a crescente importância do estado de Minas Gerais neste setor. Em especial, Belo Horizonte tem se destacado como o principal pólo de biotecnologia da América Latina (FIEMG, 2000). $\mathrm{O}$ que tem despertado o interesse e a atenção de estudiosos e políticos é a evolução significativa do setor em todo o estado mineiro que possuía apenas nove companhias em operação em 1990 - que foram as que deram origem à Fundação Biominas como instituição representante - e passou para 53 empresas em 1999, incluindo a presença de grandes multinacionais como Monsanto, Syngenta e Aventis (Baêta et al., 2002). Além da forte presença da bioindústria no estado de Minas Gerais, outro aspecto que confere destaque à região, é o fato de a primeira companhia de biotecnologia do Brasil conhecida internacionalmente - a BIOBRÁS S/A - ter se instalado na região nos anos 1970 .

De acordo com Fajnzylber (2001), um levantamento realizado pela Biominas para o Ministério da Ciência e Tecnologia (MCT) em 2001 demonstrou que Minas Gerais apresenta o maior número de empresas nas áreas de saúde humana e animal, de sinergia e meio ambiente. Das 131 empresas 
que operam nestes setores e que foram identificadas pela pesquisa, 63 localizam-se neste estado, enquanto 32 companhias encontram-se em São Paulo.

Atualmente, das 304 empresas de biotecnologia verificadas em todo o Brasil, 30\%, ou seja, aproximadamente 89 empresas, encontram-se distribuídas em todo o estado de Minas Gerais. Dessas, “... cerca de 60 empresas (70\% do total) estão localizadas em Belo Horizonte e cidades muito próximas, constituindo a cidade na mais importante base bioindustrial do País" (Judice \& Baêta, 2002:8).

A evolução da distribuição das empresas de biotecnologia em Minas Gerais de acordo com suas áreas de aplicação encontra-se na Tabela 6. Em 1999, 64\% das empresas de biotecnologia encontravam-se na área de saúde humana e, em 2001 , esse percentual reduziu-se para 51\%. Houve, na verdade, uma redução do grau de concentração neste setor e também um pequeno decréscimo no número de empresas no setor de agribusiness, em contrapartida, observou-se certo aumento na área ambiental e outros, que inclui serviços, fornecedores e insumos industriais.

Percebe-se, portanto, que apesar de verificar-se a presença de empresas em diversos segmentos dentro da chamada bioindústria, há na aglomeração de empresas de Belo Horizonte certa especialização na área de saúde humana, que engloba os segmentos de diagnóstico, farmacêutico, fitoterápico e biomateriais. Outro aspecto a destacar diz respeito ao fato de que a bioindústria de Belo Horizonte é fundamentalmente composta por empresas de pequeno porte. Trabalhos empíricos recentes mostram que aproximadamente um terço das empresas possuem até 15 empregados e $11 \%$ tem entre 16 a 30 postos de trabalho (Fajnzylber, 2001).

\subsection{Interações entre agentes, aprendizado e inovações}

A pesquisa de campo analisada no âmbito deste trabalho foi efetuada mediante entrevistas com 19 empresas localizadas em Belo Horizonte. ${ }^{25}$ Foram entrevistadas 12 empresas da área de saúde humana (sendo nove de diagnóstico),

25 A amostra inicial, de 38 empresas, foi calculada considerando a presença de 60 empresas no APL, conforme dados da Tabela 4, informados por Judice \& Baêta (2002). Entretanto, esse número de entrevistas não pode ser atingido em função de seguidas negativas por parte das empresas em atender o pesquisador. Com isso, não se tem uma amostra estatisticamente representativa, como no caso anterior. 
TABELA 6

Distribuição das empresas de biotecnologia por segmentos de mercado e percentuais individuais de participação por segmentos em estados de maior concentração, 2001

\begin{tabular}{|c|c|c|c|c|c|c|c|}
\hline \multirow[b]{2}{*}{ Segmento de Mercado } & \multicolumn{2}{|c|}{$\begin{array}{c}\text { Diretório de } \\
\text { empresas }(N=304)\end{array}$} & \multicolumn{5}{|c|}{$\begin{array}{l}\text { Diretório de empresas } \\
\text { Estados de maior concentração } \\
n=272(90 \% \text { de } N)\end{array}$} \\
\hline & $\mathrm{N}^{\circ}$ & $\%$ & $\begin{array}{c}\text { SP } \\
(n=129)\end{array}$ & $\begin{array}{c}\text { MG } \\
(n=89)\end{array}$ & $\begin{array}{c}\text { RJ } \\
(n=28)\end{array}$ & $\begin{array}{c}\text { PR } \\
(n=16)\end{array}$ & $\begin{array}{c}\text { DF } \\
(n=10)\end{array}$ \\
\hline Saúde humana (1) & 74 & 24,3 & 16 & 41 & 43 & 25 & - \\
\hline Saúde humana, animal e vegetal (2) & 14 & 4,6 & 4 & 7 & - & - & 20 \\
\hline Saúde animal (3) & 14 & 4,6 & 2 & 6 & - & 6 & - \\
\hline Agronegócio (4) & 37 & 12,2 & 10 & 9 & 11 & 31 & 50 \\
\hline Meio ambiente (5) & 14 & 4,6 & 1,5 & 10 & 7 & - & 10 \\
\hline Instrumental complementar (6) & 11 & 3,6 & 4 & 0,5 & - & 6 & 10 \\
\hline Química fina/enzima (7) & 18 & 5,9 & 4 & 0,5 & - & 6 & - \\
\hline Sinergia (8) & 15 & 4,9 & 1,5 & 10 & 4 & - & - \\
\hline Fornecedores (9) & 51 & 16,8 & 30 & 8 & 4 & 6 & - \\
\hline Multinacionais, públicas, genéricos & 56 & 18,4 & 27 & 8 & 32 & 19 & 10 \\
\hline TOTAL & 304 & 100 & 100 & 100 & 100 & 100 & 100 \\
\hline
\end{tabular}

Fonte: Biominas, 2001.

(1) Diagnósticos, fármacos, fitoterápicos, vacinas, soros e biodiversidade.

(2) Identificação genética, análise de transgênicos

(3) Veterinária, reprodução animal, pet, vacinas, probióticos, aquacultura.

(4) Melhoramento de plantas, transgênicos, produtos florestais, plantas ornamentais e medicinais, bioinsenticidas, biofertilizantes, inoculantes, flores.

(5) Biorremediação, tratamento de resíduos, análises.

(6) Software, internet, bioinformática, e-commerce, P\&D.

(7) Química fina, enzimas.

(8) Biomateriais, biomedicinas, consultoria em biotecnologia.

(9) Equipamentos, insumos e suprimentos. 
uma de saúde animal, três de biomateriais, duas de meio ambiente e uma de produtos químicos. A amostra foi composta por 15 microempresas, ou seja, possuem menos de 19 empregados, e são responsáveis por 56,3\% dos empregos gerados. O restante da amostra (4 empresas) foi composta por pequenas empresas, sendo que a maior delas possui 46 funcionários.

Quanto ao perfil dos sócios fundadores, identificou-se que a maioria deles, aproximadamente $79 \%$, são homens. A idade varia entre 30 e 60 anos e, quanto à escolaridade, $89,5 \%$ das empresas entrevistadas possuem sócios fundadores com curso superior completo ou pós-graduação. Por meio das entrevistas percebeu-se ainda que, além de empresários que participam ativamente do dia-a-dia da empresa, eles geralmente exercem uma outra profissão, na maioria das vezes, são professores ou médicos. $\mathrm{O}$ alto nível de escolaridade encontrado entre os empresários também ocorre entre o pessoal ocupado nas empresas. Por exemplo, nas micro empresas entrevistadas, do total de 166 empregados, aproximadamente $51 \%$ possuem ensino superior completo ou pós-graduação.

O resultado da aplicação dos questionários também mostrou que o aspecto que influenciou fortemente a concentração da bioindústria em Belo Horizonte foi, de fato, a presença da UFMG e das várias outras instituições de ensino e pesquisa presentes na região. Verificou-se durante as entrevistas que a maioria dos empresários possuem sua formação nestas instituições, sem contar que, muitas vezes, as empresas surgiram a partir dos resultados de pesquisas realizadas em seu interior.

O questionamento sobre as atividades de inovação feito às empresas mostrou um quadro compatível com o padrão de concorrência em um setor tecnologicamente avançado, onde as inovações cumprem papel fundamental na competitividade empresarial (Tabela 7). Entre as empresas entrevistadas, nove empresas $(47,4 \%$ do total), desenvolveram um produto novo para a sua empresa, mas que já existia no mercado, enquanto sete empresas desenvolveram um produto novo para o mercado nacional. Aproximadamente $16 \%$ das empresas da amostra (três empresas) conseguiram desenvolver um produto novo para o mercado internacional. Todas as empresas da amostra desenvolveram algum tipo de inovação no período compreendido entre os anos 2000 e 2002. 
TABELA 7

Inovações entre 2000 e 2002, Belo Horizonte (MG)

Tipo de Inovação

Micro

Sim

Pequena

Sim

\section{Inovações de produto}

1.2 Produto novo para a sua empresa, mas já existente no mercado?

7

2

1.3 Produto novo para o mercado nacional?

5

2

1.4 Produto novo para o mercado internacional?

\section{Inovações de processo}

2.1 Processos tecnológicos novos para a sua empresa, mas já existentes no setor?

\section{Outros tipos de inovação}

3.1 Criação ou melhoria substancial, do ponto de vista tecnológico, do modo de acondicionamento de produtos (embalagem)?

3.2 Inovações no desenho de produtos?

\section{Realização de mudanças organizacionais (inovações organizacionais)}

4.1 Implementação de técnicas avançadas de gestão?

4.2 Implementação de significativas mudanças na estrutura organizacional?

4.3 Mudanças significativas nos conceitos e/ou práticas de marketing?

4.4 Mudanças significativas nos conceitos e/ou práticas de comercialização? 
No que tange às inovaçóes de processo, aproximadamente $31,6 \%$ das empresas de biotecnologia entrevistadas (seis empresas) introduziram um processo tecnológico novo para a sua empresa, mas já existente no mercado e $26,3 \%$ (cinco empresas) introduziram um processo novo para o setor, o que significa que $58 \%$ das empresas entrevistadas realizaram algum tipo de inovação de processo. Inovações no acondicionamento e no desenho dos produtos também foram notificadas pelas empresas, $36,8 \%$ e 10,5\% respectivamente.

Quanto às inovações organizacionais, alguns itens merecem destaque. Aproximadamente 57,9\% das empresas da amostra (11 empresas) realizaram mudanças significativas nos conceitos e/ou práticas de comercialização, enquanto 13 empresas $(68,4 \%$ do total) relataram ter implementado novos métodos de gerenciamento visando atender às normas de certificação (ISO 9000, ISSO 14000, etc.).

Como exemplos de inovação para o mercado internacional, foram citados nas entrevistas: Anel de Ferrara, produto oftalmológico para correção de deficiências visuais, assim como os instrumentos utilizados na cirurgia para implante do mesmo (produto e técnicas patenteados no exterior); OSTEOSYNT ${ }^{\circledR}$ e ORBITALSYNT ${ }^{\circledR}$, próteses ósseas desenvolvidas com biomateriais produzidos a partir de biocerâmicas de fosfato de cálcio (produtos patenteados); IgM-GIPL ELISA (teste para diagnóstico de toxoplasmose); vacina contra leishmaniose (produto patenteado). A despeito da dificuldade de obter informaçôes mais precisas sobre o caráter das inovações empreendidas pelas empresas, a descrição destes produtos pelos entrevistados nos leva a concluir tratar-se de inovações de fato, classificadas como radicais pela literatura, e não adaptações de produtos já existentes.

As respostas sobre a atividade de inovação foram seguidas de questionamento sobre as principais fontes de informação utilizadas pelas empresas. No que tange às fontes internas de informaçôes, pode-se perceber por meio das informações do Tabela 8 que, para as micro e pequenas empresas de biotecnologia da amostra, as mais importantes são o departamento de $\mathrm{P} \& \mathrm{D}$, a área de produção e área de vendas e marketing (índices de acima de 0,80, com exceção da área de vendas e marketing para as micro empresas). Como informações advindas de fontes externas, destacaram-se como mais relevantes os clientes e fornecedores de insumos, com índices que se situaram entre 0,67 
TABELA 8

Caracterização da amostra de micro e pequenas empresas do arranjo produtivo local de biotecnologia em BH quanto à importância das fontes de informação, 2004

Descrição

Fontes internas

Departamento de P\&D

Área de produção

Áreas de vendas e marketing

Serviços de atendimento ao cliente

Outras

\section{Fontes externas}

Outras empresas dentro do grupo

Empresas associadas (joint venture)

Fornecedores de insumos (equipamentos, materiais)

Clientes

Concorrentes

Outras empresas do setor

Empresas de consultoria
Micro

Índice de Relevância* Índice de Relevância*

\section{Universidades e outros institutos de pesquisa}

Universidades

Institutos de Pesquisa

Centros de capacitação profissional, de assistência

técnica e de manutenção

Instituições de testes, ensaios e certificações

\section{Outras fontes de informação}

Licenças, patentes e know-how

Conferências, seminários, cursos e publicações especializadas

Feiras, exibições e lojas

Encontros de lazer (clubes, restaurantes, etc.)

Associações empresariais locais (inclusive consórcios de exportações)

0,60

0,65

Informações de rede baseadas na internet ou computador 
e 0,80. O papel das universidades e institutos de pesquisa foi destacado, em especial pelas microempresas, com índice de 0,82 . Por fim, em relação a outras fontes destacou-se nas duas faixas de tamanho de empresas as informaçôes advindas da rede de computadores e as obtidas em conferências, seminários e similares. As pequenas empresas atribuíram importância também a feiras e afins.

As respostas a essa questão indicaram um padrão de concorrência fortemente baseado no conhecimento, com empresas empreendendo esforços de aprendizado por meio de gastos dedicados a P\&D, bem como estabelecendo relações externas de modo a obter as informações necessárias ao aprendizado para a inovação. Entretanto, a presença reduzida no APL de produtores que compóem a cadeia produtiva da bioindústria age como fator restritivo ao estabelecimento de relaçôes que poderiam gerar externalidades e potencializar os mecanismos de aprendizado. Ao ser questionadas sobre vantagens intrínsecas à localização em Belo Horizonte, as empresas destacaram principalmente "disponibilidade de mão-de-obra qualificada", resultado do número expressivo de instituições de ensino, pesquisa e capacitação profissional, e a presença da Fundação Biominas (referência feita no item "outras vantagens"). ${ }^{26}$ Certo destaque também foi dado ao item "disponibilidade de serviços técnicos especializados”.

\section{Considerações finais}

A análise de informações acerca da atividade de inovação por pequenas empresas brasileiras presentes em aglomerações em setores tecnologicamente avançados mostrou aspectos que se apresentam promissores, em termos de considerar as aglomeraçôes como estruturas adequadas para promover atividades de inovação que se originam, em grande medida, de parcerias com as instituições de ensino/pesquisa. A despeito da sua importância ainda reduzida em termos de geração de renda e emprego no conjunto da economia e, no caso da aglomeração de empresas de biotecnologia de Belo Horizonte, também no próprio município, são estruturas responsáveis por tornar estas localidades em referência nacional em suas áreas de atuação.

26 Nessa questão, uma empresa entrevistada citou como vantagem da localidade o acesso a capital de risco. Há indicações de que há um processo, ainda incipiente, de formação de fundos de capital de risco para as empresas de biotecnologia em Belo Horizonte (Instituto Euvaldo Lodi, 2004). 
Em síntese, a pesquisa realizada junto a uma amostra de micro, pequenas e médias empresas presentes nas aglomerações de eletrônica e telecomunicações de Santa Rita do Sapucaí e na de biotecnologia de Belo Horizonte, ambas no estado de Minas Gerais, mostrou os seguintes aspectos:

- as empresas possuem atividades formais ou informais de P\&D, dedicando parcela do faturamento para esse fim;

- em geral, as empresas originaram-se de spillovers das atividades acadêmicas e possuem tanto na gerência quanto na produção um alto percentual de pessoal qualificado, com índices de escolaridade bastante elevados;

- há esforços significativos de aprendizado, tanto a partir de fontes internas quanto de relaçooes externas, em geral com as instituições de ensino / pesquisa presentes nas localidades;

- o percentual de inovações identificadas como sendo inovações para o setor de atuação é bastante elevado, inclusive daquelas assinaladas como inovaçōes em nível internacional;

- a geração de conhecimento para a inovação decorreu, em grande medida, das interaçóes com as instituiçóes locais de ensino/pesquisa, um dos elementos que a pesquisa acadêmica assinala como característico de aglomerações de empresas.

Nos termos desenvolvidos na seção 2 deste trabalho, a presença de pessoal qualificado garante flexibilidade estratégica às empresas e as tornam aptas a estabelecer relações com fontes externas de tecnologia - especialmente importantes para empresas de pequeno porte em setores de fronteira -, que complementam atividades internas de pesquisa, formais ou informais.

Nos setores em tela, a inovação e atualização tecnológica é uma condição de sobrevivência, dados os avanços rápidos e substanciais que vivenciam. Nos casos analisados, a sobrevivência e a permanência de empresas de pequeno porte está relacionada, em grande medida, às condiçôes existentes nos APLs. São estas condiçóes que permitiram a estas empresas apresentar um comportamento diferenciado em termos de inovação, em que pese os enormes percalços pelos quais passaram as empresas brasileiras com as mudanças implementadas na década de 1990. 
No caso do APL de Santa Rita do Sapucaí, a presença das instituições de ensino e pesquisa garante a permanente qualificação e atualização da mão-deobra, a utilização dos seus laboratórios por parte das empresas e a conseqüente interação entre empresas e instituições de pesquisa daí advindas, bem como o nascimento de novas empresas por meio de suas incubadoras. Em outras palavras, são as externalidades geradas por estas instituições que suportam as atividades produtivas das PEs presentes nesses municípios, tornando real a conhecida proposição marshalliana sobre a rápida difusão de informações que têm lugar nas aglomerações produtivas. Foram estas instituições que permitiram a esse pequeno município mudar a sua tradição econômica com o peso que adquiriu o setor de eletrônica e telecomunicações no conjunto das suas atividades produtivas, e ser atualmente uma das referências nesta área no Brasil. O reconhecimento dos fatores locais na competitividade das empresas foi amplamente explicitado pelas empresas, em especial nos itens qualidade e custo da mão-de-obra e proximidade com instituições de ensino/pesquisa.

Em relação ao APL de biotecnologia de Belo Horizonte, trata-se de uma aglomeração de formação mais recente e situada em uma área metropolitana, onde a sua participação no conjunto das atividades produtivas é muito inferior ao verificado no outro caso analisado. Entretanto, importância semelhante deve ser atribuída às instituições de ensino/pesquisa presentes nesse município, bem como à Fundação Biominas. Foi o acúmulo de conhecimentos científicos gerados na UFMG e demais instituições de pesquisa que permitiu a existência de uma massa crítica da qual se originaram as empresas de biotecnologia, grande parte delas por meio de incubação na Fundação Biominas. Tais instituições também suportam as atividades de inovação das empresas por meio de oferta de mão-de-obra qualificada, utilização de laboratórios para pesquisas e testes e apoio à incubação de empresas.

Entretanto, em que pesem tais semelhanças, as pesquisas realizadas encontraram, em relação à estrutura de governança, situações diferenciadas. Enquanto no APL de Santa Rita do Sapucaí há um claro reconhecimento por parte das empresas do papel da ETE e INATEL na governança local, o mesmo não se verifica em Belo Horizonte. Nesta localidade, as diversas instituições de apoio presentes não têm os seus papéis claramente definidos, havendo fortes disputas por espaços de atuação. Esta situação aparece refletida no 
parco reconhecimento que as empresas têm do papel das instituições de apoio para a sua competitividade. Por este motivo, detectou-se que as empresas têm dificuldades de separar o que são as suas dificuldades conjunturais e estruturais, daquelas oriundas de problemas com a governança local.

Da análise das condições existentes nestas duas aglomerações de empresas, foi possível, portanto, perceber o importante papel das instituições de ensino/pesquisa na geração de externalidades que suportam a atividade de inovação e, consequentemente, a competitividade das empresas nelas localizadas. Os limites identificados pela pesquisa à geração de externalidades se situam, grosso modo, na ausência de vínculos mais consistentes entre empresas e entre estas e instituições de apoio (especialmente no caso de Belo Horizonte), bem como pela ausência de elos importantes das cadeias produtivas nos dois APLs.

Para finalizar, assinale-se, primeiramente, que os resultados obtidos pelas empresas nestas duas localidades não são generalizáveis. As características observadas em APLs são únicas, dado que decorrentes de elementos culturais, sociais, econômicos e políticos singulares que concorrem para a sua constituição. Outro aspecto importante a destacar é que a trajetória futura destas aglomerações depende também, e em grande medida, da dinâmica da economia brasileira. As transformações substanciais por que passam os setores analisados requerem recursos e instrumentos de política industrial que ultrapassam as possibilidades das localidades, considerando a alta centralização de instrumentos de política econômica existente na economia brasileira. 


\section{Referências bibliográficas}

Acs, J.Z.; Audretsch, D.B., Innovation and Small Firms, Massachusetts: MIT Press, 1990.

Audretsch, D.B. Small Business in Industrial Economics: the new learning. Revue d'Economie Industriell, n. 67, 1994.

Audretsch, D.B.; Vivarelli, M., "Small firms and R\&D spillovers: Evidence from Italy", Revue d'Economie Industriell, n.67, 1994.

Baêta, A.M.C. et al.. Small And Medium-Sized Biotechnology Companies in The State of Minas Gerais - Innovation And Clusters Development. 6th Conference on Technology Policy and Innovation: Integrating Regional and Global Iniciatives in the Learning Society. KIOTO: ICTPI KANSAI Science City, 2002.

Baptista, R.; Swann, P, “Do firms in clusters innovate more?”, Research Policy, n.27, p.525-540, 1990.

BIOMinaS. Parque Nacional de Empresas de Biotecnologia. Mimeo, BIOMINAS, Belo Horizonte, 2001.

Carlsson, B.O., "Flexibility and the theory of the firm", International Journal of Industrial Organization, n.7, p.179-203, 1989.

Cassiolato, J.E.; Szapiro, M., Arranjos e sistemas produtivos e inovativos locais no Brasil. IE/UFRJ, Rio de Janeiro, 2002. Disponível em www.ie.ufrj.br/redesist.

Cassiolato, J.E.; Brito, J.N.P.; Vargas, M.A., "Arranjos cooperativos e inovação na indústria brasileira”, in Negri, J.A.; Salerno, M.S. (orgs.), Inovaçôes, Padrões Tecnológicos e Desempenho das Firmas Industriais Brasileiras, Rio de Janeiro: IPEA, 2005.

Dosi, G., "Sources, Procedures, and Microeconomics Effects of Innovation”, Journal of Economic Literature, vol. XXVI, p.120-1171, set., 1988.

Fajnzylber, P., Fatores de Competitividade e Barreiras ao Crescimento no Pólo de Biotecnologia de Belo Horizonte, Belo Horizonte: Departamento de Economia/ CEDEPLAR, 2001.

FIEMG, Cluster de Biotecnologia: Belo Horizonte-Minas Gerais/Brasil, Mimeo, FIEMG, Belo Horizonte, 2000.

FINEP, CNI e MCT, $A$ indústria e a questão tecnológica, Brasília, 2002. 
Galli, R.; Teubal, M., Paradigmatic Shifts in National Innovation Systems. Systems of Innovation: Technologies, Institutions and Organizations, Londres e Washington:. Pinter, p.342-70, 1997.

INATEL, Santa Rita do Sapucaí. Disponível em: www.inatel.br. Acesso em: 17 ago.2004.

Instituto Euvaldo L., "Diagnóstico do Setor de Biotecnologia em Minas Gerais Desafios Rumo a 2010", Resumo Executivo, Belo Horizonte, 2004.

Judice, V.M.M.; Baêta, A.M.C., "Clusters em Bioindústria e Biotecnologia em Minas Gerais - habitats construídos de inovação, competitividade e desenvolvimento regional. Gestão \& Tecnologia”, Revista Fundação Pedro Leopoldo, Pedro Leopoldo: v.1, p.155-70, 2002.

Lemos, M.B., A Construção de Redes Locais de Inovação sob Condiçōes Periféricas: o Caso da Biotecnologia na Aglomeração de Belo Horizonte, CEDEPLAR/ UFMG, 1998.

OECD, Small and Medium-sized Enterprises: Technology and Competitiveness, Paris, 1993.

OECD, Boosting Innovation - The Cluster Approach, Paris, 1999.

Pavitt, K., "Some foundations for a theory of the large innovating firm", in Dosi, G.; Giannetti, R.; Toninelli, P.A., Technology and Enterprise in a Historical perspective, Oxford: Clarendon Press, 1992.

PINTEC, Pesquisa Industrial Inovação Tecnológica 2000, FINEP, IBGE, MCT e MPOG, Rio de Janeiro, 2000.

, Pesquisa Industrial Inovação Tecnológica 2000, FINEP, IBGE, MCT E MPOG, Rio de Janeiro, 2003.

Piore, M.J.; Sabel. C.F., The Second Industrial Divide: Possibilities for Prosperity, Nova York: Basic Books, 1984.

Rizzoni, A., "Technology and organization in small firms: an interpretative framework", Revue D'Économie Industriell, n.67, 1994.

Rothwell, R.; Beesley, M., "The importance of technology transfer", in Barber, J.; Metcalfe, J.S.; Porteus, M., Barriers to Growth in Small Firms, Londres e Nova York: Routledge, 1989. 
Sabel, C. et al., Regional prosperities compared: Massachussets and BadenWürttemberg. HILPERT, U. Regional Innovation and Decentralization - High tech industry and government policy, Londres: Routledge, 1991.

Souza, M.C.A.F., Pequenas e médias empresas na reestruturação industrial. Ed. SEBRAE, 1995.

Steindl, J., Pequeno e grande capital, São Paulo: Ed. Hucitec/Ed. Unicamp, 1990.

Storey, D.J.; Tether, B.S., "Public policy measures to support new tecnology-based firms in the European Union", Research Policy, v.26, n.9, p.1.037-1.057,1998.

Symeonidis, G., "Innovation, Firm Size and Market Structure: Schumpeterian Hypotheses and some new themes", Paris: OECD Economic Studies, n.27, 1996.

Tether, B.S.; Smith, I.J.; Thwaites, A.T., "Smaller enterprises and innovation in the UK: the SPRU Innovations Database revisited”, Research Policy, n.26, p.19-32, 1997.

Utterback, J.M., Dominando a Dinâmica da Inovação, Rio de Janeiro: Ed. Qualitymark, 1996.

ENDEREÇOS PARA CORRESPONDÊNCIA:

Marisa dos Reis A. Botelho-botelhomr@ufu.br

Rua Hélio Lima Santa Cecília, n 61 Bairro Morada da Colina, Uberlândia, MG CEP 38 411-168

Michelle de Castro Carrijo - michellecarrijo@yahoo.com.br

Rua da Amora, n³12 Bairro Pacaembu, Uberlândia, MG CEP 38.401-532

Gilsa Yumi Kamasaki - gkamasaki@yahoo.com.br

QMSW 5 - Lote 2 Edificio Montblanc D-202 Sudoeste, Brasília, DF CEP 70680-500 